\title{
Cardiopulmonary Resuscitation Success Rates in 402 Patients with and without Renal Impairment at Canada’s Largest Community Hospital
}

Tabo Sikaneta ${ }^{1,2 *}$, Babak Aliazardeh², Nasim Khosrodad ${ }^{1}$, Umang Moody¹, Sara Mahdavi², Megan Christie ${ }^{1}$, Edwin Chu ${ }^{1}$, Julie Ting ${ }^{1}$, Robert Ting $^{1,2}$, Jason Fung ${ }^{1,2}$, Gordon Nagai ${ }^{1,2}$, Paul Ng ${ }^{1,2}$, Denise Tam ${ }^{1,2}$, Simon Tsui ${ }^{1,2}$, Janet Roscoe ${ }^{2}$ and Paul Tam ${ }^{1,2}$

${ }^{1}$ Nephrology Associates, Scarborough, ON, Canada

${ }^{2}$ The Scarborough Hospital, Scarborough, ON, Canada

\begin{abstract}
Background: Success rates after in-hospital cardiopulmonary resuscitation have been reported to be worse in patients with renal failure. However, renal failure was not well characterized in these reports, and rarely incorporated estimates of glomerular filtration rates.
\end{abstract}

Objective: We reviewed all on-site adult cardiac arrests at our institution during an 8-year period. Cardiopulmonary resuscitation success was defined as survival to discharge. Renal function was considered impaired if a pre-arrest estimate of glomerular filtration rate was less than $60 \mathrm{ml}$ per $\min$ per $1.73 \mathrm{~m}^{2}$.

Results: Cardiopulmonary resuscitation was successful in $31(7.7 \%)$ of 402 patients. Renal impairment predated cardiac arrest in $73.6 \%$ patients, was the most common of the examined pre-arrest morbidities, but did not associate with cardiopulmonary resuscitation success rates (OR=0.92, 95\% $\mathrm{Cl} 0.40-2.12)$.

Conclusions: Pre-cardiac arrest renal impairment, defined using estimates of glomerular filtration rate of less than $60 \mathrm{ml}$ per min per $1.73 \mathrm{~m}^{2}$, was surprisingly common but did not significantly influence cardiopulmonary resuscitation success rates.

Keywords: Cardiopulmonary arrest; Cardiopulmonary resuscitation; Chronic kidney disease; Acute kidney injury

\section{Introduction}

CPR success rates vary widely depending on the type of health care setting and in the characteristics of the patients studied. When defined as survival to discharge, CPR success rates range from $0 \%$ to $42 \%$ [1]. Despite this, several trends have been identified. Improved CPR success rates have been demonstrated with active cardiac disease (presenting as a shockable rhythm) as the proximate cause of arrest [2]. Success rates are worse if the arrest is unwitnessed or unmonitored, if the patient is elderly or non-white, or if asystole or pulseless electrical activity is the initial cardiac rhythm [3-6]. In addition, certain pre-arrest comorbidities such as pneumonia, sepsis, shock requiring vasopressor medication use, metastatic disease, gastrointestinal hemorrhage, and renal failure are poor prognostic factors [2,5,7-10].

Renal failure has generally been poorly defined or characterized in these studies. For example, GFR estimates or measurements were rarely used, and most studies did not differentiate between patients with acute or chronic renal failure, between patients with different stages of CKD, or between patients receiving different types and vintages of dialysis. Bedell reported CPR success in only $2(3 \%)$ of 75 patients with renal failure, (defined by a blood urea nitrogen concentration greater than $50 \mathrm{mg}$ per deciliter $(18 \mu \mathrm{mol}$ per liter) [7]. Tian reported worse CPR success rates for patients with renal insufficiency in a cohort of 49,656 patients who arrested in the intensive care unit, but did not define renal insufficiency [5]. Ebell found that reduced kidney function (defined as a serum creatinine level greater than $1.5 \mathrm{mg}$ per deciliter $(130 \mu \mathrm{mol}$ per liter) negatively predicted CPR success in 225 patients (OR for dying 5.44, $\mathrm{p}<0.001)$. When defined in a further 106 patients as a serum creatinine level greater than $2.5 \mathrm{mg}$ per deciliter (220 mol per liter), the odds ratio for dying were $5.8(\mathrm{p}<0.001)$ [2]. Compared to a control group of 247 non-dialysis patients, Moss reported a CPR success rate of $8 \%$ versus $12 \%$ in 74 dialysis patients [11]. Lafrance, however, found that $79 \%$ of 24 patients who had received CPR after arresting while on hemodialysis were alive and discharged from hospital 30 days later [12].
As the incidence of renal disease rises, health care providers can increasingly expect to have end-of-life discussions and to attempt resuscitation efforts for patients with a widening spectrum of kidney diseases $[13,14]$. The main purpose of this study was to determine success rates of CPR performed on inpatients admitted to the two sites of a large community hospital in Scarborough, Ontario. The secondary aim was to assess the effect of various pre-morbid conditions (with a focus on renal impairment as defined by a reduced eGFR) that may have influenced their CPR outcomes.

\section{Methods}

Study design, setting and participants: We used a historical cohort design. After need for informed consent was waived by our hospital ethics review board, the hospital records of all adults suffering inhospital cardiac arrests in the years 1996 to 2005 inclusive were screened. Patients were included for further analysis if they were greater than 18 years old, and if their cardiac arrest occurred on the premises of one of the two sites of The Scarborough Hospital. For patients with multiple cardiac arrests, only the first arrest was examined. Patients were excluded from analysis if pulselessness was not documented, if there was not a report filled out at time of arrest, or if the arrest occurred off hospital premises. Patients who died after resuscitation efforts lasting 10 minutes or less were deemed at risk of not having received full-out resuscitation efforts, and were also excluded from analysis.

*Corresponding author: Tabo Sikaneta, Nephrology Associates, Scarborough, ON, Canada, E-mail: tabosikaneta@yahoo.ca

Received July 03, 2013; Accepted August 22, 2013; Published August 25, 2013

Citation: Sikaneta T, Aliazardeh B, Khosrodad N, Moody U, Mahdavi S, et al (2013) Cardiopulmonary Resuscitation Success Rates in 402 Patients with and without Renal Impairment at Canada's Largest Community Hospital. J Nephrol Ther 3: 136. doi:10.4172/2161-0959.1000136

Copyright: ( $) 2013$ Sikaneta T, et al. This is an open-access article distributed under the terms of the Creative Commons Attribution License, which permits unrestricted use, distribution, and reproduction in any medium, provided the original author and source are credited. 
Citation: Sikaneta T, Aliazardeh B, Khosrodad N, Moody U, Mahdavi S, et al. (2013) Cardiopulmonary Resuscitation Success Rates in 402 Patients with and without Renal Impairment at Canada's Largest Community Hospital. J Nephrol Ther 3: 136. doi:10.4172/2161-0959.1000136

Page 2 of 4

Information on selected demographics and co morbidities (history of coronary artery disease, hypertension, diabetes mellitus, pneumonia, sepsis, and metastatic cancer), details of arrest (initial cardiac rhythm, duration of arrest attempt, and outcome), as well as information on available renal function parameters and renal replacement history was obtained. Estimates of GFR were made using the four-variable Modification of Diet in Renal Disease equation. Three eGFR's were sought for every patient, one closest to three months or more before admission (eGFR->3mo), one on admission (eGFR-admission), and one closest to (but before) arrest time (eGFR-arrest).

\section{Study definitions}

CPR success was defined as survival to discharge from our institution. We did not have information concerning eventual outcomes for patients who required transfer to another acute care hospital (for example for emergency cardiac surgery) and in these patients CPR was considered to have failed. A normal and abnormal eGFR were defined by a value greater or equal to, and less than $60 \mathrm{ml} /$ $\mathrm{min} / 1.73 \mathrm{~m}^{2}$ respectively. Normal renal function was present when all recorded eGFR's were normal, even if only one was available. Renal function was deemed unknown if no eGFR's were available. Renal impairment was defined as the presence of any abnormal eGFR, and categorized into the following mutually exclusive groups: Acute kidney injury if one of eGFR-admission or eGFR-arrest was normal and the other abnormal; chronic kidney disease if both eGFR->3mo and one (or both if available) of eGFR-admission and eGFR-arrest was abnormal (further classified by lowest eGFR value into stage 3 $\left(30-59.9 \mathrm{ml} / \mathrm{min} / 1.73 \mathrm{~m}^{2}\right)$, stage $4\left(15-29.9 \mathrm{ml} / \mathrm{min} / 1.73 \mathrm{~m}^{2}\right)$, or stage 5 (less than $15 \mathrm{ml} / \mathrm{min} / 1.73 \mathrm{~m}^{2}$ ); and dialysis-dependent renal failure if any form of renal replacement therapy (including continuous renal replacement therapy) was provided during the admission when the arrest occurred. It was considered acute if initiated less than three months before arrest date. Unspecified renal disease was defined by at least one abnormal eGFR but when none of the above definitions fit. It typically encompassed patients who had only one eGFR value that was abnormal.

\section{Study outcomes}

The primary outcome was CPR success, defined based on discharge from hospital status. This was a dichotomous measure that took success or failure as binary values. Secondary objectives were to test the association between study outcome and renal impairment, metastatic cancer, pneumonia, coronary artery disease, diabetes mellitus, hypertension, sepsis, and initial cardiac rhythm.

\section{Statistical analysis}

Data was entered into an Access database and after cleaning and additional coding transferred to SPSS version 18 for analysis. Univariate descriptive analyses were conducted to examine demographic variables and clinical characteristics of study population. Bivariate analyses were conducted to assess association between specific variables including study outcome and independent factors like demographic variables, pre-existing conditions, renal status, initial cardiac rhythm, and CPR duration. T test and analysis of variance were used to describe the relationship between independent continuous variables like age and dependent variables, and Pearson Chi-square test, or Fisher's Exact test if appropriate, was used for categorical variables. Multivariate logistic regression analyses were conducted to explore effect of renal function status on study outcome by computing adjusted odds ratios after removing confounding effects and identifying potential interaction effects.

\section{Results}

There were relatively few patients who suffered a cardiac arrest during 1997 and 1999, and it was not deemed effective to pull and examine their microfiche records. There were 899 cardiac arrests over the other 8 study years of 1996, 1998, and 2000 to 2005 . Four hundred two met selection criteria and were analyzed further. Descriptive statistics are presented in table 1 . Mean age at time of arrest was $71( \pm$ 13) years. Most patients died within the first 24 hours, and $4.7 \%$ of those who survived beyond 24 hours died in a neuro-vegetative state. CPR was successful in only 31 (7.7\%) of 402 patients. Successful patients received a mean of 6.8 minutes of resuscitation, while unsuccessful patients received a mean 20.5 minutes of attempted CPR.

Two hundred ninety-six patients (73.6\%) had renal impairment. No differences were seen in presenting cardiac rhythms between groups of patients with and without renal impairment. Three hundred sixty-one patients $(89.9 \%)$ had either or both of coronary artery disease or renal impairment, while 378 (94\%) had one or more of diabetes, hypertension, coronary artery disease or renal impairment. There was considerable overlap between renal impairment and coronary artery disease: $76 \%$ of patients with coronary artery disease had evidence for renal impairment, and $70.3 \%$ of patients with renal impairment had a history of coronary artery disease. Renal impairment was also seen in $86(60 \%)$ of the 143 patients who did not have a history of diabetes mellitus or hypertension, and $36(60 \%)$ of the 60 patients who did not have a history of diabetes mellitus, hypertension or coronary artery disease.

Univariate analysis (Table 2) showed no significant association between the presence of renal impairment and CPR success (odds ratio 0.92 , 95\%CIs $0.40-2.12$ ). Hypertension was the only examined premorbid diagnosis that significantly associated with CPR outcome both in univariate and multivariate analysis (Table 3 ).

Table 4 highlights subgroups of patients with renal impairment

\begin{tabular}{|c|c|c|c|}
\hline \multirow[t]{2}{*}{ Variable } & \multirow[t]{2}{*}{$\begin{array}{c}\text { Number }(\%) \text { (within } \\
\text { column) }\end{array}$} & \multicolumn{2}{|c|}{$\begin{array}{c}\text { CPR outcome } \\
\text { Number (\%) (within column) }\end{array}$} \\
\hline & & Successful & Unsuccessful \\
\hline Total & $402(100 \%)$ & $31(7.7 \%)$ & $371(92.3 \%)$ \\
\hline Age (years, SD) & $71 \pm 13$ & $70.9 \pm 13$ & $71.4 \pm 12.7$ \\
\hline \multicolumn{4}{|l|}{ Sex } \\
\hline Women & $179(45.1 \%)$ & $15(48.4 \%)$ & $164(44.8 \%)$ \\
\hline Men & $218(54.9 \%)$ & $15(51.6 \%)$ & $201(55.2 \%)$ \\
\hline CPR duration (minutes) & 19.6 & $6.78 \pm 6.0$ & $20.5 \pm 14.3$ \\
\hline \multicolumn{4}{|l|}{ Comorbidities } \\
\hline Hypertension & $199(49.5 \%)$ & $24(77.4 \%)$ & $175(47.2 \%)$ \\
\hline Diabetes mellitus & $155(38.6 \%)$ & $12(38.7 \%)$ & $143(38.5 \%)$ \\
\hline Coronary artery disease & $273(67.9 \%)$ & $22(71.0 \%)$ & $251(67.7 \%)$ \\
\hline Pneumonia & $80(19.9 \%)$ & $2(6.5 \%)$ & $78(21 \%)$ \\
\hline Sepsis & $61(15.2 \%)$ & $1(3.2 \%)$ & $60(16.2 \%)$ \\
\hline Metastatic cancer & $60(14.9 \%)$ & $4(12.9 \%)$ & $56(15.1 \%)$ \\
\hline Renal impairment & $296(73.6 \%)$ & $23(74.2 \%)$ & $273(73.6 \%)$ \\
\hline \multicolumn{4}{|l|}{ Initial cardiac rhythm } \\
\hline Asystole & $182(48.3 \%)$ & $5(17.9 \%)$ & $177(50.7 \%)$ \\
\hline Atrial fibrillation & $2(0.5 \%)$ & $1(3.6 \%)$ & $1(0.3 \%)$ \\
\hline Pulseless electrical arrest & $108(28.6 \%)$ & $10(35.7 \%)$ & $98(28.1 \%)$ \\
\hline Pacemaker beat & $7(1.9 \%)$ & $0(0.0 \%)$ & $7(2 \%)$ \\
\hline $\begin{array}{l}\text { Ventricular fibrillation/ } \\
\text { tachycardia }\end{array}$ & 78(19.4\%) & $12(38.7 \%)$ & $66(17.8 \%)$ \\
\hline Unknown & $25(6.2 \%)$ & $3(9.7 \%)$ & $22(5.9 \%)$ \\
\hline
\end{tabular}

Table 1: Descriptive characteristics of patients. 
Citation: Sikaneta T, Aliazardeh B, Khosrodad N, Moody U, Mahdavi S, et al. (2013) Cardiopulmonary Resuscitation Success Rates in 402 Patients with and without Renal Impairment at Canada's Largest Community Hospital. J Nephrol Ther 3: 136. doi:10.4172/2161-0959.1000136

Page 3 of 4

\begin{tabular}{|c|c|c|c|c|}
\hline Condition/Characteristic & $\begin{array}{c}\text { Number of } \\
\text { Successful CPRs } \\
\text { (\%) }\end{array}$ & $\begin{array}{c}\text { Odds } \\
\text { Ratio }\end{array}$ & $\begin{array}{c}\mathbf{9 5 \%} \\
\text { Interval }\end{array}$ & p-value \\
\hline Renal impairment & $23(7.9 \%)$ & 0.92 & $0.40-2.12$ & 0.840 \\
\hline Coronary artery disease & $22(8.1 \%)$ & 1.17 & $0.52-2.61$ & 0.704 \\
\hline Hypertension & $24(12.1 \%)$ & 3.84 & $1.61-9.13$ & 0.001 \\
\hline Diabetes mellitus & $12(7.7 \%)$ & 1.00 & $0.47-2.14$ & 0.986 \\
\hline Pneumonia & $2(2.5 \%)$ & 0.26 & $0.06-1.11$ & 0.06 \\
\hline Sepsis & $1(1.6 \%)$ & 0.17 & $0.02-1.29$ & 0.054 \\
\hline Metastatic cancer & $4(6.7 \%)$ & 0.83 & $0.28-2.47$ & 0.742 \\
\hline Initial cardiac rhythm & & & & \\
\hline Asystole & $5(2.7 \%)$ & 0.21 & $0.08-0.56$ & 0.001 \\
\hline Pulseless electrical arrest & $10(9.3 \%)$ & 1.33 & $0.60-2.91$ & 0.481 \\
\hline $\begin{array}{c}\text { Ventricular tachycardia/ } \\
\text { fibrillation }\end{array}$ & $12(15.4 \%)$ & 2.92 & $1.35-6.30$ & 0.005 \\
\hline Atrial fibrillation & $1(50 \%)$ & 12.33 & $0.75-202.14$ & 0.025 \\
\hline $\begin{array}{c}\text { Unknown initial cardiac } \\
\text { rhythm }\end{array}$ & $3(12 \%)$ & 1.70 & $0.48-6.03$ & 0.407 \\
\hline
\end{tabular}

Table 2: Unadjusted odds ratios for CPR success according to presence of certain pre-morbid conditions and to initial cardiac rhythm.

\begin{tabular}{|c|c|c|c|}
\hline Variable Name & Odds Ratio & $\begin{array}{c}\text { Interval for Odds } \\
\text { Ratio }\end{array}$ & p-value \\
\hline Hypertension & 3.67 & $1.46-9.23$ & 0.006 \\
\hline Sepsis & 0.20 & $0.03-1.60$ & 0.131 \\
\hline Pneumonia & 0.26 & $0.06-1.19$ & 0.082 \\
\hline Asystole & 0.27 & $0.09-0.79$ & 0.017 \\
\hline Ventricular tachycardia/fibrillation & 2.00 & $0.83-4.82$ & 0.123 \\
\hline Renal status & & & \\
\hline Normal & Reference & Reference & \\
\hline Unknown & 0.72 & $0.14-3.57$ & 0.687 \\
\hline Acute kidney injury & 0.75 & $0.12-4.50$ & 0.755 \\
\hline Chronic kidney disease & 0.47 & $0.11-2.01$ & 0.310 \\
\hline Dialysis-dependent & 0.67 & $0.18-2.61$ & 0.590 \\
\hline Unspecified renal disease & 0.48 & $0.14-1.64$ & 0.244 \\
\hline
\end{tabular}

Table 3: Multivariate logistic regression model of factors associated with success in CPR.

in whom non-statistically significant differences in CPR success rates were found.

\section{Discussion}

Our study was concerned with determining CPR success rates at our large community hospital, and examining previously reported as well as unreported factors, with a focus on eGFR-defined renal impairment, that might influence these rates. CPR was successful in only $31(7.7 \%)$ of 402 patients who arrested on the premises of our hospital between the years 1996 to 2005 . We were able to reproduce some of the findings previously reported including worse success rates in patients presenting with asystole and improved rates in patients presenting with ventricular arrthymias. We did not, however, find CPR success rates to be any different for the group of patients with renal impairment (OR 0.92, 95\% CI 0.40-2.12). Our survival rate was low and undermined our power to derive statistically significant associations.

Two novel findings of this study were the demonstration of markedly improved CPR success rates in patients with a history of hypertension (OR 3.84, $\mathrm{p}=0.001,95 \%$ CI 1.61-9.13), and that patients with renal impairment as defined by reduced eGFR comprised such a large proportion of patients with in-hospital cardiac arrest (296 (73.6\%) of 402 patients had pre-arrest eGFRs less than $60 \mathrm{ml} / \mathrm{min}$ ). To our knowledge an association between a pre-arrest history of hypertension and CPR success rates has not previously been reported upon. We speculate that some of the advantage to a pre-arrest history of hypertension that we observed reflects the beneficial use of some of the antihypertensive medications that the patients may have been receiving pre-arrest. However, despite an apparent survival advantage, (12.1 versus $3.4 \%$ of patients with and without hypertension surviving cardiac arrest), a history of hypertension was still quite prevalent (199 of 402 patients) with $87.9 \%$ of these 199 patients dying after CP arrest. This finding, if confirmed in other studies, should therefore not detract from the well-known harmful effects of hypertension on cardiac events, but rather aid future efforts to understand factors affecting cardiac arrest outcomes.

Our finding that renal impairment was present in $73.6 \%$ of 402 cardiac arrest patients ( $81 \%$ if the 32 patients with no available renal function test results are excluded) suggests that renal impairment is an important risk factor for fatal cardiac arrhythmias in the general hospitalized patient. This is consistent with the demonstration in numerous studies that approximately half of all deaths in patients with CKD are attributed to cardiac disease, with half of these being due to fatal cardiac arrhythmias $[15,16]$. Fatal cardiac arrhythmias are less common in the general population where their predominant risk factor is reported to be underlying coronary artery disease [17].

Patients with overt renal disease often have underlying structural cardiovascular disease such as left ventricular hypertrophy, cardiac fibrosis, and vascular calcification. In addition, dialysis-dependent patients are predisposed to chronic intermittent ischemia, metabolic acidosis, and frequent electrolyte fluxes. However these factors would not be expected to be as prevalent or significant in patients with more subtle or acute renal impairment. Other mechanisms therefore are likely to contribute to increased risk of cardiac arrhythmias. One interesting candidate is excessive sympathetic activity reported to be present in patients with acute and chronic kidney disorders with and without uremia $[18,19]$.

Our study has several important limitations. The number of surviving patients was too low to adequately power attempts to demonstrate significant associations between CPR success and subsets of patients with renal impairment. We planned to include 8 variables in the multiple regression analysis, including 6 variables previously shown to associate with CPR success, one (renal impairment) that we defined using eGFR criteria, and one (hypertension) that was novel.

\begin{tabular}{|l|c|c|c|c|c|}
\hline Renal Status & Number & $\begin{array}{c}\text { Success } \\
(\%)\end{array}$ & $\begin{array}{c}\text { Odds } \\
\text { Ratio }\end{array}$ & Interval & p-value \\
\hline Normal & 62 & $5(8.1 \%)$ & reference & & \\
\hline Unknown & 38 & $4(8.5 \%)$ & 0.98 & $0.22-4.34$ & 0.976 \\
\hline Acute kidney injury & 34 & $2(5.9 \%)$ & 0.71 & $0.13-3.88$ & 0.695 \\
\hline $\begin{array}{l}\text { Chronic kidney } \\
\text { disease }\end{array}$ & 63 & $4(6.3 \%)$ & 0.77 & $0.20-3.02$ & 0.711 \\
\hline -stage 3 & 17 & $2(11.8 \%)$ & 1.52 & $0.27-8.62$ & 0.636 \\
\hline -stage 4 and 5 & 46 & $2(4.3 \%)$ & 0.52 & $0.10-2.80$ & 0.445 \\
\hline $\begin{array}{c}\text {-stage 4 } \\
\text {-stage 5 }\end{array}$ & 14 & $2(6.3 \%)$ & & & \\
\hline Dialysis-dependent & 67 & $7(10.4 \%)$ & 1.33 & $0.40-4.43$ & 0.642 \\
\hline $\begin{array}{c}\text {-acutely } \\
\text {-chronically }\end{array}$ & 23 & $1(4.3 \%)$ & 0.52 & $0.06-4.69$ & 0.518 \\
\hline $\begin{array}{c}\text {-vintage } \\
\text { unknown }\end{array}$ & 15 & $\mathbf{1 ( 1 7 . 2 \% )}$ & 2.37 & $0.63-8.96$ & 0.202 \\
\hline $\begin{array}{c}\text { Unspecified renal } \\
\text { disease }\end{array}$ & 137 & $10(7.2 \%)$ & 0.81 & $0.09-7.53$ & 0.856 \\
\hline
\end{tabular}

Table 4: Unadjusted odds ratios for success in CPR according to renal status. 
Citation: Sikaneta T, Aliazardeh B, Khosrodad N, Moody U, Mahdavi S, et al. (2013) Cardiopulmonary Resuscitation Success Rates in 402 Patients with and without Renal Impairment at Canada's Largest Community Hospital. J Nephrol Ther 3: 136. doi:10.4172/2161-0959.1000136

Page 4 of 4

Given that only 31 patients survived, the number of variables used as potential predictors of survival was thus relatively large compared to sample size and likely reduced the model's statistical power. The ideal sample size to test all eight variables and show an 80 percent probability of association between the dependent and independent variables would have been 54 patients. As such the chances of a type II statistical errors occurring, where weaker relationships would not be detected in the multiple regression model in presence of stronger covariates, was higher.

Secondly as a retrospective study it was prone to selection and observation bias, and to confounding. It is possible, for example, that the true incidence of coronary artery disease was higher than our methods could ascertain. This would not detract from the observed high frequency of reduced eGFR's in the 402 patients. Thirdly, our overall survival rates were lower than most reported rates. We believe this is because of our strict definitions of cardiac arrest and CPR success. For example by excluding patients with respiratory arrests (who have been shown to have improved outcomes after CPR) we likely biased our outcomes [3]. Fourthly, despite being Canada's largest urban community hospital, our hospital does not provide specialized surgical care for patients with neurosurgical or cardiac surgical issues, and it is not a trauma or transplantation centre. As such, our findings may not be applicable to other centers that manage patients who may have different risk factors for cardiac arrest. Finally, some of our definitions of renal impairment were non-conventional. For example our definition of acute kidney injury did not incorporate relative changes in renal function or urine output because this information was often not available.

However we believe our definition was able to identify both resolving and developing acute kidney injury, something most definitions of acute kidney injury do not [20].

In summary, when defined as an estimated GFR of less than 60 $\mathrm{ml} / \mathrm{min}$ per $1.73 \mathrm{~m}^{2}$, renal impairment was surprisingly common in patients who suffered an in-hospital cardiac arrest, but did not significantly associate with CPR success rates. A history of hypertension significantly associated with improved CPR success rates. Future efforts should include larger multi-centre studies to confirm or refute these findings in both hospitalized and out-of-hospital cardiac arrests, and ones to delineate whether and how renal impairment is causally associated with increased risk for cardiac arrest.

\section{References}

1. Sandroni C, Nolan J, Cavallaro F, Antonelli M (2007) In-hospital cardiac arrest: incidence, prognosis and possible measures to improve survival. Intensive Care Med 33: 237-245.

2. Ebell MH (1992) Prearrest predictors of survival following in-hospital cardiopulmonary resuscitation: a meta-analysis. J Fam Pract 34: 551-558.

3. George AL Jr, Folk BP 3rd, Crecelius PL, Campbell WB (1989) Pre-arrest morbidity and other correlates of survival after in-hospital cardiopulmonary arrest. Am J Med 87: 28-34.

4. Brady WJ, Gurka KK, Mehring B, Peberdy MA, O'Connor RE (2011) In-hospita cardiac arrest: impact of monitoring and witnessed event on patient survival and neurologic status at hospital discharge. Resuscitation 82: 845-852.

5. Tian J, Kaufman DA, Zarich S, Chan PS, Ong P (2010) Outcomes of critically ill patients who received cardiopulmonary resuscitation. Am J Respir Crit Care Med 182: 501-506.

6. Meaney PA, Nadkarni VM, Kern KB, Indik JH, Halperin HR, et al. (2010) Rhythms and outcomes of adult in-hospital cardiac arrest. Crit Care Med 38 : 101-108.

7. Bedell SE, Delbanco TL, Cook EF, Epstein FH (1983) Survival after cardiopulmonary resuscitation in the hospital. N Engl J Med 309: 569-576.

8. Rozenbaum EA, Shenkman L (1988) Predicting outcome of inhospital cardiopulmonary resuscitation. Crit Care Med 16: 583-586.

9. de Vos R, Koster RW, De Haan RJ, Oosting H, van der Wouw PA, et al. (1999) In-hospital cardiopulmonary resuscitation: prearrest morbidity and outcome. Arch Intern Med 159: 845-850.

10. Taffet GE, Teasdale TA, Luchi RJ (1988) In-hospital cardiopulmonary resuscitation. JAMA 260: 2069-2072.

11. Moss AH, Holley JL, Upton MB (1992) Outcomes of cardiopulmonary resuscitation in dialysis patients. J Am Soc Nephrol 3: 1238-1243.

12. Lafrance JP, Nolin L, Senecal L, Leblanc M (2006) Predictors and outcome of cardiopulmonary resuscitation (CPR) calls in a large haemodialysis unit over a seven-year period. Nephrol Dial Transplant 21: 1006-1012.

13. Schaubel DE, Morrison HI, Desmeules M, Parsons D, Fenton SS (1998) Endstage renal disease projections for Canada to 2005 using Poisson and Markov models. Int J Epidemiol 27: 274-281.

14. Gilbertson DT, Liu J, Xue JL, Louis TA, Solid CA, et al. (2005) Projecting the number of patients with end-stage renal disease in the United States to the year 2015. J Am Soc Nephrol 16: 3736-3741.

15. Pun PH, Smarz TR, Honeycutt EF, Shaw LK, Al-Khatib SM, et al. (2009) Chronic kidney disease is associated with increased risk of sudden cardiac death among patients with coronary artery disease. Kidney Int 76: 652-658.

16. (2012) Atlas of End-Stage Renal Disease in the United States Chapter 9 Special Studies. Cardiovascular Special Studies, USRDS Annual Data Report 2: 337.

17. Demirovic J, Myerburg RJ (1994) Epidemiology of sudden coronary death: an overview. Prog Cardiovasc Dis 37: 39-48.

18. Schlaich MP, Socratous F, Hennebry S, Eikelis N, Lambert EA, et al. (2009) Sympathetic activation in chronic renal failure. J Am Soc Nephrol 20: 933-939.

19. Koomans HA, Blankestijn PJ, Joles JA (2004) Sympathetic hyperactivity in chronic renal failure: a wake-up call. J Am Soc Nephrol 15: 524-537.

20. Zavada J, Hoste E, Cartin-Ceba R, Calzavacca P, Gajic O, et al. (2010) A comparison of three methods to estimate baseline creatinine for RIFLE classification. Nephrol Dial Transplant 25: 3911-3918. 